\title{
AFLP Characterization of the Mexican Pineapple Germplasm Collection
}

\author{
Ermis Yanes Paz \\ Centro de Bioplantas, Universidad de Ciego de Avila, Carretera a Morón Km. 9, CP 069450, Ciego \\ de Ávila Cuba \\ Katia Gil \\ Department of Genetic Engineering, CINVESTAV, Unidad Irapuato, Apdo. Postal 629, Irapuato, \\ Guanajuato, Mexico
}

Laureano Rebolledo, Andrés Rebolledo, and Daniel Uriza

Campo Experimental Papaloapan, INIFAP, Veracruz, Mexico

Octavio Martínez

Department of Genetic Engineering, CINVESTAV, Unidad Irapuato, Apdo. Postal 629, Irapuato, Guanajuato, Mexico

\author{
Miriam Isidrón \\ Centro de Bioplantas, Universidad de Ciego de Avila, Carretera a Morón Km. 9, CP 069450, Ciego \\ de Ávila Cuba \\ June Simpson 1 \\ Department of Genetic Engineering, CINVESTAV, Unidad Irapuato, Apdo. Postal 629, Irapuato, \\ Guanajuato, Mexico
}

\begin{abstract}
The Mexican pineapple germplasm collection represents the genetic diversity of cultivated pineapple [Ananas comosus (L.) Merr.] in that country and includes important genotypes from Hawaii, Ivory Coast, and Latin America. The collection has been partially characterized at the morphological level, but a molecular characterization has been lacking. With this aim, 39 genotypes of $A$. comosus var. comosus Coppens \& Leal, two of A. comosus var. bracteatus (Lindl) Coppens \& Leal, two of $A$. comosus var. ananassoides (Baker) Coppens \& Leal, and three from the related genus Bromelia $\mathrm{L}$. were analyzed with a total of 169 amplified fragment length polymorphism (AFLP) markers. A dendrogram representing the genetic relationships between these samples based on the AFLP results, showed a low level of diversity in the Mexican pineapple collection. In general, the molecular classification of the materials agreed well with the morphological classification. Several groups of genotypes showed distances of $<0.03$, whereas others thought to be similar based on morphological criteria were found to be distant. These results will allow more efficient use of the materials in the germplasm collection for breeding purposes and support the acquisition of genotypes that are scarce or lacking in the collection.
\end{abstract}

Pineapple is one of the most important tropical fruits and world production exceeded 14.6 million $t$ in 2003 (FAO, 2004). Until recently, $\approx 70 \%$ of pineapple production was based on a single cultivar, 'Smooth Cayenne', which monopolized the market. In the past few years, however, the cultivar DelMonte Gold (MD-2) has also become popular and captured a significant share of the fresh-fruit market (Coppens d'Eeckenbrugge et al., 1997). Reflecting this situation, most breeding programs are also centered on a few leading cultivars and neglect much of the germplasm diversity of the existing genetic pool. This omission is exacerbated by the incomplete characterization of pineapple germplasm and unsolved taxonomical complexities.

Several pineapple germplasm collections exist. The most important are the collection maintained by Empresa Brasilera de Pesquisas Agropecuarias/Centro Nacional de Pesquisas de Mandioca

Received for publication 9 Mar. 2004. Accepted for publication 13 June 2004. We are grateful to Drs. Luis Herrera-Estrella and Alba Jofre y Garfias for the critical reading of the manuscript and to CONACyT Mexico for financial support from the collaborative program between Mexico and Cuba under grant number J200.1677/2001/2002.

Corresponding author: e-mail: jsimpson@irA.cinvestav.mx y Fruticultura (EMBRAPA/CNPMF) in Cruz das Almas, Brazil, that of Centro Internacional de la Recherche Agricole-Departement Productions Fruitierres et Horticoles (CIRAD-FLHOR) in Martinique, and the U.S. Dept. of Agriculture collection in Hawaii. These collections have been partially characterized with morphological descriptors (Coppens d'Eeckenbrugge et al., 1997; Duval et al., 2001; Ferreira and Cabral, 1993; Leal et al., 1986). Other countries including Mexico have smaller but nonetheless important collections since they represent the genetic diversity of the cultivated pineapple in that particular country. Most of the genotypes in the Mexican pineapple germplasm collection at the Instituto Nacional de Investigaciones Forestales y Agropecuarios (INIFAP) experimental station at Papaloapan, Veracruz, Mexico, have been obtained from farmers or through exchanges with other collections (A. Rebolledo, personal communication).

Pineapple taxonomy has been seriously criticized (Coppens d'Eeckenbrugge et al., 1997; Duval and Coppens d'Eeckenbrugge, 1993) since the previously accepted taxonomic key was based on traits that depend on single genes or vary greatly with the environment. A thorough revision of this system has recently been proposed by Coppens d'Eeckenbrugge and Leal (2003). They suggest a simplified system where all pineapples are 
grouped under one genus that includes two species. The seven species previously accepted by Smith and Downs (1979) are now described as five botanical varieties of $A$. comosus. The classification proposed by Coppens d'Eeckenbrugge and Leal (2003) has been used throughout this report, but both old and new classifications are presented in Table 1 in order to avoid confusion. Within cultivated pineapple genotypes, attempts have also been made to classify germplasm into horticultural groups based on morphological characteristics; however, this may have led to the association of very distinct genotypes within a single group based on a few outstanding phenotypic traits (Duval and Coppens d'Eeckenbrugge, 1993; Duval et al., 1996).

Isozyme polymorphism has been used previously in the genus Ananas Mill. to clarify taxonomical aspects (Aradhya et al., 1994; De Wald et al., 1992; García, 1988). However, due to the low number of markers, the scope of these studies is limited. More recently, Duval et al. $(2001,2003)$ used RFLP markers and chloroplast genotypes to study genetic diversity in pineapple. Three hundred and one accessions covering the genus Ananas were tested. Compared to the results obtained with isozymes in Ananas, RFLP revealed a higher level of polymorphism since $41 \%$ of the probes were polymorphic.

The RFLP technique is extremely robust but expensive and time-consuming (Kochert, 1994). In the case of chloroplast markers, DNA from this organelle must be isolated increasing the complexity of the analysis and the data may not always be informative when individuals of a single species are analyzed. AFLP markers (Vos et al., 1995) have been widely used in other species to study diversity (Breyne et al., 1999; Coulibaly et al., 2003), identify cultivars (Dirlenwanger et al., 1998), and carry out classical genetic mapping studies. The possibility to detect low levels of polymorphism makes it the method of choice for intra-species analysis. The AFLP technique is also very reproducible with a high multiplex ratio, combining the robustness of the RFLP method with the efficiency and simplicity of polymerase chain reaction (PCR)-based methods. Two preliminary reports (Kato et al., 2001; Tapia et al., 2001) have demonstrated the usefulness of AFLP for the study of closely related, cultivated and noncultivated pineapple genotypes.

In this work, AFLP markers were used to assess the genetic diversity of the Mexican pineapple germplasm collection. The objectives were to determine the diversity of the collection which represents both commercial cultivars grown in Mexico and germplasm used in ongoing breeding programs. The results of the study are of importance in planning the acquisition of new material for the collection and in designing new breeding programs. The suitability of AFLP to study diversity in pineapple is also discussed.

\section{Materials and Methods}

Forty-six genotypes, including 39 genotypes of $A$. comosus var. comosus, two genotypes of $A$. comosus var. ananassoides, two genotypes of $A$. comosus var. bracteatus, and three other related species of the genus Bromelia, belonging to the Mexican National Pineapple Germplasm Collection at the INIFAP experimental station at Papaloapan, Veracruz, were analyzed (Table 1). The classification used in this article corresponds with that of Coppens d'Eeckenbrugge and Leal (2003), and cultivar names are the common names used locally. We have also indicated the species and the horticultural group and the previously accepted classification.
Leaf samples were obtained from plants growing in the field and transported in dry ice. DNA extraction was performed according to Dellaporta et al. (1993), with minor modifications. AFLP analysis was carried out according to Vos et al. (1995).

The oligonucleotide primers used for the preamplification step were:

EcoRI (EcoRI+A) 5'-AGACTGCGTACCAATTC/A-3', MseI (MseI+A) 5'-GACGATGAGTCCTGAGTAA/A-3'

The preamplification step was followed by a second selective amplification step using three selective nucleotides. The EcoRI primer was kept constant with the selective nucleotides AAT whereas the Mse I primer varied with addition of an extra AG, TG, GT, or CC.

Autoradiograms were analyzed visually and scored as $1=$ presence of band, $0=$ absence of band. Genetic distances were calculated using the S-Plus 2000 for Windows software package (Mathsoft, Seattle, Wash.) using the simple matching coefficient (Skroch et al., 1992). Cluster analysis was based on distance matrices using the unweighted pair group method with arithmetic averages (UPGMA) and relationships between samples were graphically presented as dendrograms. Confidence limits on relationships were determined by bootstrap analysis $(B=1500$ replicates) (Felsenstein, 1985).

\section{Results and Discussion}

A total of 169 scorable AFLP markers were generated with four primer combinations (Table 2). The levels of polymorphism were as follows: $98.2 \%$ polymorphism considering both the genera Ananas and Bromelia, 73.3\% among samples from the genus Ananas, and $63.9 \%$ considering only A. comosus var. comosus. In comparison, Duval et al. (2001), using RFLP markers found 94.4\% polymorphism among 294 accessions covering the genus Ananas and $74.7 \%$ when 167 accessions of $A$. comosus var. comosus were analyzed. However, these results are not directly comparable to this work since here a much narrower collection of germplasm was analyzed. The percentages of polymorphism obtained with each AFLP primer combination are shown (Table 2).

With the exception of 'Hawaii IV' and 'Hawaii IX,' which have identical genotypes, all samples were differentiated by the AFLP technique (Fig. 1). The related species of the genus Bromelia 'Cardón Borrego' (Bromelia penguin L.), 'Che ornato' (Bromelia sp.), and 'Ornato epífita' (Bromelia sp.) were clearly separated from the genus Ananas, which forms a large distinct group. Within the genus Ananas, 'Ornamental Costa Rica' (A. comosus var. ananassoides) a noncultivated genotype was separated from the other genotypes. However, 'Tricolor Roja' and 'Tricolor Verde' (Ananas comosus var. bracteatus) grouped with the A. comosus var. comosus genotypes as did 'Wild Brazil' (A. comosus var. ananassoides). This result was unexpected since initial studies (Duval and Coppens d'Eeckenbrugge, 1993; Duval et al., 1996, 2003) did not indicate that A. comosus, A. bracteatus Baker, and A. ananassoides Baker L.B. Smith (under the previous classification) were so closely related. However, under the recently revised classification, A. comosus, A. bracteatus, and A. ananas (L.B. Smith) L.B. Smith are no longer regarded as distinct species but as botanical varieties of the single species, A. comosus (Coppens d'Eeckenbrugge and Leal, 2003). The results presented here therefore support this revised classification. The single exception which lies outside the group (Fig. 1) is the accession 'Ornamental Costa Rica' (A. comosus var. ananassoides) previously classified as $A$. nanus (L.B. Smith) L.B. Smith. This result suggests the need 
Table 1. Pineapple cultivars and relatives analyzed in this study indicating old and new classifications, horticultural groups, and origin.

\begin{tabular}{|c|c|c|c|c|c|}
\hline $\begin{array}{l}\text { Sample } \\
\text { no. }\end{array}$ & $\begin{array}{c}\text { Previous } \\
\text { classification }\end{array}$ & $\begin{array}{c}\text { New } \\
\text { classification }\end{array}$ & Cultivar & $\begin{array}{l}\text { Horticultural } \\
\text { group }\end{array}$ & Origin \\
\hline$\overline{1}$ & Bromelia pinguin & |-------------- & Cardón Borrego & None & Mexico \\
\hline 2 & Bromelia sp. & ----------------- & Bromelia Epífita & None & Mexico \\
\hline 3 & Bromelia sp. & ----------------- & Ché Ornato & None & Mexico \\
\hline 4 & Ananas nanus & A. comosus var. ananassoides & Ornamental Costa Rica & None & Costa Rica \\
\hline 5 & A. bracteatus & A. comosus var. bracteatus & Tricolor Roja & None & Ivory Coast \\
\hline 6 & A. bracteatus & A. comosus var. bracteatus & Tricolor Verde & None & Ivory Coast \\
\hline 7 & A. ananassoides & A. comosus var. ananassoides & Wild Brazil & None & Puerto Rico \\
\hline 8 & A. comosus & A. comosus var. comosus & Pernambuco & Pernambuco & Puerto Rico \\
\hline 9 & A. comosus & A. comosus var. comosus & Introduction 1 & Maipure & Puerto Rico \\
\hline 10 & A. comosus & A. comosus var. comosus & Manzana & Maipure & Colombia \\
\hline 11 & A.s comosus & A. comosus var. comosus & Introduction 2 & Spanish & Costa Rica \\
\hline 12 & A. comosus & A. comosus var. comosus & Spanish Red & Spanish & Puerto Rico \\
\hline 13 & A. comosus & A. comosus var. comosus & PR-1-56 & Cayenne/Spanish & Puerto Rico \\
\hline 14 & A. comosus & A. comosus var. comosus & PR-1-67 & Cayenne/Spanish & Puerto Rico \\
\hline 15 & A. comosus & A. comosus var. comosus & Cabezona Carranza & Spanish & Mexico \\
\hline 16 & A. comosus & A. comosus var. comosus & Cabezona Tabasco & Spanish & Mexico \\
\hline 17 & A. comosus & A. comosus var. comosus & Esmeralda & Smooth Cayenne & Mexico \\
\hline 18 & A. comosus & A. comosus var. comosus & Criolla Quintana Roo & Spanish & Mexico \\
\hline 19 & A. comosus & A. comosus var. comosus & Criolla Nayarit & Spanish & Mexico \\
\hline 20 & A. comosus & A. comosus var. comosus & Criolla Guerrero & Spanish & Mexico \\
\hline 21 & A. comosus & A. comosus var. comosus & Veracruz & Smooth Cayenne & Mexico \\
\hline 22 & A. comosus & A. comosus var. comosus & Quintana Roo & Smooth Cayenne & Mexico \\
\hline 23 & A. comosus & A. comosus var. comosus & Rayada Azueta & Smooth Cayenne & Mexico \\
\hline 24 & A. comosus & A. comosus var. comosus & Rayada N3 & Smooth Cayenne & Mexico \\
\hline 25 & A. comosus & A. comosus var. comosus & Hojasverdes & Smooth Cayenne & Mexico \\
\hline 26 & A. comosus & A. comosus var. comosus & Extravigor & Smooth Cayenne & Mexico \\
\hline 27 & A. comosus & A. comosus var. comosus & Hawaii I & Smooth Cayenne & Hawaii \\
\hline 28 & A comosus & A. comosus var. comosus & Hawaii II & Smooth Cayenne & Hawaii \\
\hline 29 & A. comosus & A. comosus var. comosus & Hawaii III & Smooth Cayenne & Hawaii \\
\hline 30 & A. comosus & A. comosus var. comosus & Hawaii IV & Smooth Cayenne & Hawaii \\
\hline 31 & A. comosus & A. comosus var. comosus & Hawaii VI & Smooth Cayenne & Hawaii \\
\hline 32 & A. comosus & A. comosus var. comosus & Hawaii VIII & Smooth Cayenne & Hawaii \\
\hline 33 & A. comosus & A. comosus var. comosus & Hawaii IX & Smooth Cayenne & Hawaii \\
\hline 34 & A. comosus & A. comosus var. comosus & Kona & Smooth Cayenne & Hawaii \\
\hline 35 & A. comosus & A. comosus var. comosus & Libby & Smooth Cayenne & Puerto Rico \\
\hline 36 & A. comosus & A. comosus var. comosus & Dorsey Edwards & Smooth Cayenne & Puerto Rico \\
\hline 37 & A. comosus & A. comosus var. comosus & Blanca de Cuba & Pernambuco & Puerto Rico \\
\hline 38 & A comosus & A. comosus var. comosus & Champaka I & Smooth Cayenne & Costa Rica \\
\hline 39 & A. comosus & A. comosus var. comosus & Champaka II & Smooth Cayenne & Costa Rica \\
\hline 40 & A. comosus & A. comosus var. comosus & Champaka III & Smooth Cayenne & Costa Rica \\
\hline 41 & A. comosus & A. comosus var. comosus & Champaka IV & Smooth Cayenne & Costa Rica \\
\hline 42 & A. comosus & A. comosus var. comosus & KU-2 & Smooth Cayenne & Costa Rica \\
\hline 43 & A. comosus & A. comosus var. comosus & MD-1 & Smooth Cayenne & Costa Rica \\
\hline 44 & A. comosus & A. comosus var. comosus & MD-2 INIFAP & Smooth Cayenne & Costa Rica \\
\hline 45 & A. comosus & A. comosus var. comosus & MD-2 GOBVer & Smooth Cayenne & Costa Rica \\
\hline 46 & A. comosus & A. comosus var. comosus & MD-2 Azueta & Smooth Cayenne & Costa Rica \\
\hline
\end{tabular}

Table 2. List of AFLP primer combinations, number of markers, and levels of polymorphism.

\begin{tabular}{lccccc}
\hline $\begin{array}{l}\text { Primer } \\
\text { combination }\end{array}$ & $\begin{array}{c}\text { Markers } \\
\text { (no.) }\end{array}$ & $\begin{array}{c}\text { Total } \\
\text { polymorphic } \\
\text { markers } \\
\text { (no.) }\end{array}$ & $\begin{array}{c}\text { Level of } \\
\text { polymorphism } \\
(\%)\end{array}$ & $\begin{array}{c}\text { Polymorphic } \\
\text { markers in } \\
\text { Ananas } \\
\text { (no.) }\end{array}$ & $\begin{array}{c}\text { Level of } \\
\text { polymorphism } \\
(\%)\end{array}$ \\
\hline Mse-AAG & 22 & 22 & 100 & 16 & 72.7 \\
Mse AAC & 44 & 44 & 100 & 30 & 68.2 \\
Mse-AGT & 39 & 36 & 92 & 26 & 66.6 \\
Mse ATG & 64 & 64 & 100 & 52 & 81.2 \\
\hline
\end{tabular}




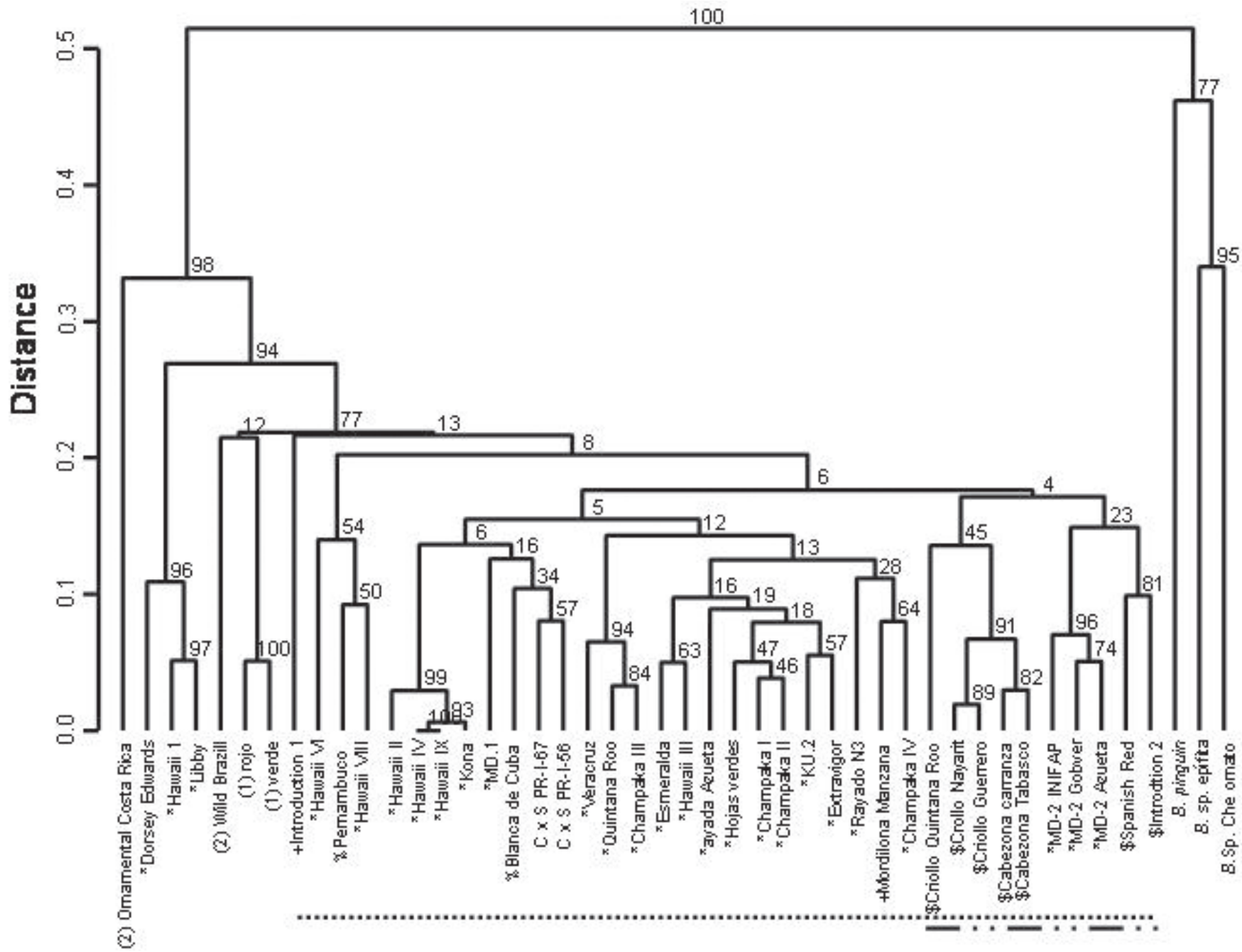

Fig. 1. Dendrogram showing the diversity of the Mexican pineapple germplasm collection. Accessions are presented with cultivar names. Ananas comosus botanical varieties are represented as 1) A. comosus var. bracteatus, 2) A. comosus var. ananassoides. Horticultural groups of A. comosus var. comosus are represented as follows: $*$ Smooth Cayenne, $\$=$ Spanish, $+=$ Maipure, $\%=$ Pernambuco, $\mathrm{C} \times \mathrm{S}=$ Cayenne/Spanish hybrids, group of Smooth Cayenne cultivars $=\bullet \bullet \bullet \bullet \bullet$ group of Spanish cultivars $=-\bullet \bullet-$.

for a more detailed analysis of A. comosus var. ananassoides at the genotype level including many more accessions in order to clarify the classification of this group.

The greatest genetic distance $(0.51)$ was found between members of the different genera Ananas and Bromelia. However, within each genus notable differences were also observed. A distance of 0.47 was found between Bromelia pinguin 'Cardón Borrego' and the other two Bromelia accessions and these other two accessions were separated by a distance of 0.34 . The distance between Ananas comosus var. ananassoides 'Ornamental Costa Rica' and the other Ananas accessions was 0.32 , whereas the other members of Ananas sp. were found to group at distances less than 0.27 . Three small groups showed very high similarity with distances of less than 0.03 , suggesting that these materials are essentially the same genotypes: 1) 'Cabezona Carranza'/“Cabezona Tabasco';2) 'Hawai II'/'Hawai IV’/'HawaiIX'/'Kona';3) ‘Criolla Guerrero'/‘Criolla Nayarit'.

The bootstrap values shown on the dendrogram give an indication of how robust the different groupings on the dendrogram are. Higher numbers indicate nodes that are found in the majority of the bootstrap samples, whereas low numbers indicate that these nodes are not so consistent. In terms of these values, the analysis presented here shows some interesting results. As mentioned above the samples from the related genus Bromelia, clearly form a separate group as do 'Ornamental Costa Rica' and 'Dorsey Edward', 'Hawaii I', and 'Libby' with bootstrap values of 100, 98, and 94 respectively. A fourth group with a high bootstrap number of 77 contains the majority of the samples, including A. comosus var. bracteatus and A. comosus var. ananassoides as well as most of the A. comosus var. comosus samples. Within this fourth group however many of the bootstrap values at the nodes are extremely low, suggesting that these nodes were not very consistent during the bootstrap analysis. This indicates that the samples within this group are genotypically quite similar and that the groups formed are distinguished by few AFLP bands.

In general, the results obtained from the AFLP analysis agree well with the morphological characterization of the germplasm collection. However some interesting differences were observed. The materials in the three clusters with distances $<0.03$ commented above were also classified as the same or closely related genotypes morphologically. This is also the case for the accessions 'Champaka I' and 'Champaka II'. 
In a broad sense, all the Smooth Cayenne accessions are found within a single large group (••• in Fig. 1), although Spanish, Pernambuco, and Maipure cultivars are also found dispersed within this group. The surprising exceptions to this arrangement are the accessions Smooth Cayenne: 'Dorsey Edwards', 'Hawaii I', and 'Libby', which are outwith the group. Another compact cluster consistent with the morphological classification is that denoted $-\cdots-$ on the dendrogram. This cluster contains all the samples classified as Spanish and within the group three improved cultivars classified as Smooth Cayenne: 'MD-2 INIFAP', 'MD-2 Azueta', and 'MD-2 GOBVer'. This grouping may suggest that these latter cultivars have been crossed with Spanish germplasm at some point during their development.

In contrast, the recognized hybrids from Smooth Cayenne $x$ Spanish crosses 'PR-1-67', and 'PR-1-56' clearly group within the Smooth Cayenne cluster.

At the cultivar level, the most notable differences between the morphological classification and the molecular classification are the separation of members of the Pernambuco and Maipure horticultural groups (\% and + respectively in Fig. 1), which rather than form groupings together are mixed within the Smooth Cayenne group. Duval and Coppens d'Eeckenbrugge (1993) and Duval et al. (1996) have suggested that some of the horticultural groups determined for pineapple may in fact associate cultivars with quite different genotypes that share a common outstanding morphological feature such as "piping" along the leaf edges as in the case of the Maipure group. This may explain the differences observed in this study for the Pernambuco and Maipure classes.

Most genotypes of the Mexican collection are derived from Smooth Cayenne clones (Table 1), with a few accessions derived from Spanish clones. This indicates that the genetic basis of the Mexican germplasm collection is very narrow. Other genotypes, although present in the collection, are not cultivated in Mexico and not widely used for breeding purposes. The information presented here could serve as the basis for the organization and development of the Mexican pineapple germplasm collection. For the collection to be more representative of the broad spectrum of pineapple germplasm, it should be enriched with more cultivated and non-cultivated genotypes. A core collection could be constructed taking into account the data presented here. For example 'Hawaii IV', 'Hawaii IX', 'Kona', and 'Hawaii II' are very similar genotypes; therefore in subsequent genotype analysis a single example of these accessions would be sufficient. This could also be done with 'Esmeralda' and 'Hawaii III' and with 'PR-I-67' and 'PR-I-58', etc. This core collection, although having fewer genotypes, would represent the genetic diversity of the complete collection and could be characterized extensively both at the morphological level and genetically in a more cost-effective manner. The potential of the AFLP technique to distinguish even very closely related accessions as shown here would also permit the study of variation within clones obtained from the same mother plant and from plants reproduced in tissue culture.

\section{Literature Cited}

Aradhya, M., F. Zee, and R.M. Manshardt. 1994. Isozyme variation in cultivated and wild pineapple. Euphytica 79:87-99.

Breyne, P., D. Rombaut, A. Van Gysel, M. Van Montagu, and T. Gerats. 1999. AFLP analysis of genetic diversity within and between Arabidopsis thaliana ecotypes. Mol. Gen. Genet. 261:627-634.

Coppens d'Eeckenbrugge, G., F. Leal, and M.F. Duval. 1997. Germplasm resources of pineapple. Hort. Rev. 21:133-175.

Coppens d'Eeckenbrugge, G. and F. Leal. 2003. Morphology, anatomy and taxonomy, p. 13-32. In: D.P. Bartholomew, R.E. Paull, and K.G. Rohrbach (eds.). The Pineapple: Botany, production and uses. CABI, Wallingford, U.K.

Coulibaly, I., B. Revol, M. Noirot, V. Poncet, M. Lorieux, C. CarascoLacombe, J. Minier, M. Dufour, and P. Hamon. 2003. AFLP and SSR polymorphism in a Coffea interspecific backcross progeny $(C$. heterocalyx $\times C$. canephora $\times C$. canephora. Theor. Appl. Genet. 107:1148-55.

De Wald, M.G., G.A. Moore, and W.B. Sherman. 1992. Isozymes in Ananas (pineapple): Genetics and usefulness in taxonomy. J. Amer. Soc. Hort. Sci. 117:491-496.

Dellaporta, S.L., J. Wood, and J.B. Hicks. 1993. A plant DNA minipreparation: Version II. Plant Mol. Biol. Rpt. 1:19-28.

Dirlenwanger, E., S. Duha, M.A. Viruel, and R. Saunier. 1998. Identification of peach cultivars using molecular markers. Acta Hort. 465:69-72

Duval, M.F.G. and G. Coppens d'Eeckenbrugge. 1993. Genetic variability in the genus Ananas. Acta Hort. 334:27-32.

Duval, M-F., G. Coppens d'Eeckenbrugge, F. Ferreira, J. Cabral, and B. Bianchetti. 1996. First results from joint EMBRAPA - CIRAD Ananas germplasm collecting in Brazil and French Guyana. Acta Hort. 425:137-144.

Duval, M.F., J.L. Noyer, X. Perrier, G. Coppens d'Eeckenbrugge, and P. Hamon. 2001. Molecular diversity in pineapple assessed by RFLP markers. Theor. Appl. Genet. 102:83-90.

Duval, M-F., G.S. Buso, F.R. Ferreira, J.L. Noyer, G. Coppens d'Eeckenbrugge, P. Hamon, and M.E. Ferreira. 2003. Relationships in Ananas and other related genera using chloroplast DNA restriction site variation. Genome 46:990-1004.

FAO. 2004. Faostat Agricultural Data. 18 June 2004. <http://apps. fao.org/faostat/collections?version=ext $\&$ hasbulk=0\&subset=agric ulture $>$

Felsenstein, J. 1985. Confidence limits on phylogenies: An approach using the bootstrap. Evolution 39:783-791.

Ferreira, F. and J. Cabral. 1993. Pineapple Germplasm in Brazil. Acta Hort. 334:23-26.

García, M.L. 1988. Etude taxinomique du genre Ananas. Utilisation de la variabilité enzymatique. $\mathrm{PhD}$ Thesis, Université de Sciences et Technologies de Lille, Montpelier, France.

Kato, C.Y., P.H. Moore, F. Zee, C. Nagai, D.L. Steiger, and R. Ming. 2001. Genetic diversity in pineapple assessed by AFLP markers. 18 June 2004. <http://www.intl-pag.com/pag/10/abstracts/PAGX_P531. html>.

Kochert, G. 1994. RFLP technology, p. 8-38 In: R. Phillips and I.K. Vasil (eds.). DNA-based markers in plants. Kluwer, Dordrecht, The Netherlands.

Leal, F., M.L. García, and C. Cabot. 1986. Prospección y recolección de Ananas y sus congéneres en Venezuela. Plant Genetic Resources Nwslt. 66:16-19.

Skroch, P., J. Tivang, and J. Nienhuis. 1992. Analysis of genetic relationships using RAPD marker data, p. 26-29 In: Applications of RAPD technology to plant breeding. Joint Plant Breeding Symp. Ser. Crop Sci. Soc. Amer., Amer. Soc. Hort. Sci., and Amer. Genetic Assn., 1 Nov. 1992, Minneapolis, Minn.

Smith, L.B. and R.J. Downs. 1979. Bromelioidees (Bromeliaceae). Flora Neotrópica, Monograph 14, 3:2142.

Tapia, C.E., E.M.A. Gutierrez, A.H. Guillen, L.M. Warbourton, A.D. Uriza, and M.A. Rebolledo. 2001. Characterization of pineapple germplasm (Ananas spp.) by means of AFLPs. Abstr. from the $4^{\text {th }}$ Intl. Pineapple Symp., 16-19 Apr. 2001, Veracruz, Mexico.

Vos, P., R. Hogers, M. Bleeker, M. Reijans, T. Van de Lee, M. Hornes, A. Fritjters, J. Pot, J. Peleman, M. Kuiper, and M. Zabeau. 1995. AFLP: A new technique for DNA fingerprinting. Nucleic Acids Res. 23:4407-4414. 